\title{
10. Demographic Change: How, why and consequences
}

\section{Peter McDonald}

Change is inherent to demography because demography is the study of how and why populations change. Without change, demography does not exist as a discipline.

In its simplest definition, demography is the scientific study of human populations. According to Landry (1945), the term demography was first used by the Belgian statistician Achille Guillard, in his 1855 publication Élements de statistique humaine, ou démographie comparée. However, John Graunt's Natural and political observations mentioned in a following index, and made upon the bills of mortality, published in 1662 in London, is generally acknowledged to be the first published study in the field of demography. The book demonstrated the usefulness of compilations of information relating to the population of London by presenting statistics on a wide range of characteristics such as employment, age and sex composition, health and environment. Graunt also published an early version of the life table which, having been further developed by Edmund Halley and Joshua Milne, led to the publication in 1840 of the first official life table by William Farr, compiler of scientific abstracts in the General Register Office of England and Wales. The statistical concepts of the life table remain today the fundamental elements of demographic method. The life table, perhaps better termed a death table, is a description of how the number in a population, all born on the same day, falls with age until all have died.

This chapter begins with a more detailed description of demography in terms of life transitions before moving on to a discussion of the measurement of these transitions. Next, it addresses the theory of how and why transitions occur and the association of demography with the theoretical approaches of other disciplines. Transitions are the determinants of demographic change but, as elaborated in this chapter, demography is also concerned with the consequences of change. The distinction between determinants and consequences is the basis of the subsequent discussion of policy in demography as mitigation (influencing the determinants) or adaptation (dealing with the consequences). The chapter ends with how demographers deal with future change. 


\section{Demographic transitions}

The life table describes the ages at which an event, death, occurs in a population. It provides the risk of death at any age in the population. More generally, demographic methods are concerned with describing whether and when events occur to human populations. The main events studied are childbearing, death, disease, disability, migration, entry to and exit from relationships, education and employment, and housing types or tenures. However, demographic methods can be and are applied to a much wider range of events that are experienced by human populations, theoretically to any changes in the lives of the members of a population. The study of the occurrence of several different events during a person's lifetime is referred to as life course analysis (Uhlenberg 1996).

In more conceptual terms, demography examines transitions from one state of being to a different state of being where these transitions are set in space and time. Demography is concerned with how, when, why, where and to whom these transitions occur. Measurement in demography applies concepts and methods from statistics and mathematics. Most significantly, demography measures the probabilities that a group of people in one state will remain in that state or move to another state in a fixed period of time.

The ultimate states of being are life and death and the life table describes rates of transition from life to death at any given age. Births come into being through transitions in women's (and potentially men's) childbearing histories as they move at different ages from having had no births to having one birth, or from one to two, and so on. The main focus in the demography of fertility is upon women because the range of their fertile years is narrower than is the case for men. Rates of transition from one birth to the next are called parity progression rates. There is a further dynamic involved here because as women move from one age to the next age, their chances of transitioning from one parity to the next also change, thus affecting the number of births. Parity progression is also affected considerably by the time since the previous birth (McDonald and Kippen 2011). This is an example of how decisions related to the timing of a transition affect the chance that the transition will occur and, in macro-terms, how decisions on the timing of births affect the total number of births in a given time period. This latter macro-consequence is referred to by demographers as a 'tempo effect'. Today, in countries with low birthrates, changes in the timing of births, tempo effects, are the main reason that fertility rates change from one year to the next (Bongaarts and Feeney 1998).

In addition to the fundamental demographic events of birth and death, the concepts and methods of demography provide a statistically robust way of examining numerous population transitions such as: 
- between relationship statuses

- singlehood to marriage

- singlehood to living together

- living together to marriage

- marriage to separation

- separation to divorce

- divorce to remarriage

- between different living arrangements

- at home with parents to a group household

- a group household to a couple relationship

- children at home to the 'empty nest'

- a couple relationship to living alone

- living alone to an aged care facility

- between different labour force statuses

- out of the labour force to employment

- employment to unemployment and vice versa

- employment to retirement

- between different health statuses

- no chronic illness to chronic illness

- one stage of a chronic illness to another stage

- an acute condition to recovery

- fully able to disabled

- one stage of disability to another stage

- between different health behaviours

- a smoker to a non-smoker

- a healthy weight to obesity

- active to sedentary

- between education states

- secondary school to vocational training

- secondary school to university

- university to graduation

- graduation to employment

- between housing situations

- renting to purchasing

- purchasing to full ownership

- from an apartment to a separate house 
- between places of residence

- living in a small country town to living in a metropolis

- living in one country to living in a different country

- between different states of income and social security

- living on a wage to living on a social security payment

- moving from one social security payment to another.

\section{Demographic method}

The ways of measuring these transitions can be quite complex when, in a given period of time, people can make a number of different transitions. For example, in a given year, a person may be (in statistical language) 'subject to the interrelated risks' of partnering, moving residence, and changing housing type. In the same period, they are subject to the risk of death or leaving the country in which they are living. Demography handles these multiple possibilities through increment-decrement life tables that measure how people move in and out of multiple states during a year (Preston et al. 2001). However, full application of the increment-decrement approach to transitions is highly data intensive and this is why demographers are very concerned with the collection of detailed, quantitative information on populations. High-quality data across time also allows the calculation of relative degrees of uncertainty related to transitions between states of being (Clark 2003).

\section{Theory in demography}

Theory in demography relates to explanation of why and when events occur to people; for example, explanation of:

- long life

- teenage pregnancy

- early school drop-out

- housing tenure

- contracting a disease such as HIV/AIDS and how long people live after contracting a particular disease

- why people move from rural to urban areas or change their country of residence

- why people end their relationships. 
Like other disciplines, demography draws upon knowledge in other disciplines to develop its theory. The main disciplines that contribute to demographic theory are economics, sociology, anthropology, epidemiology, geography, public health, biology, ecology and environmental science. Theory in demography is established very largely through statistically oriented comparative analysis: comparisons across space and time and across different subgroups of the population. In this regard, demography is inherently comparative. The methods used are primarily quantitative but the complexity of human behaviour often means that qualitative research methods are required.

As most life course transitions involve a decision on the part of the person making the transition, theory in demography relates to sociology, anthropology, psychology and economics. In relation to sociology and anthropology, the decisions of individuals are taken within an institutional context, and that context may favour or constrain the decision being considered. For example, very low rates of fertility in a country have been attributed to institutional constraints upon decision-making about births stemming from how women are supported in that society (McDonald 2000). Also in relation to decision-making about births, the theory of planned behaviour has been applied from psychology (Klobas 2011) and utility theory from economics (Becker 1981). Todaro (1969) provides an economic behavioural model to explain the decision to move from a rural area to a city. The same model has been used extensively to explain other population movements. Thus, theory in demography is also inherently about change: why is it that people decide to move from one state of being to another?

\section{Consequences of demographic change}

Demography is concerned also with the outcomes for populations of the occurrence of 'demographic' events, that is, with the impacts that demographic changes have upon society and the economy. Most basically, it is concerned with a population's size, age structure and geographic distribution, which are the outcomes of the events of birth, death and migration. The important demographic measure, the rate of population growth, a measure of change, is an outcome of the rates of birth, death and migration. To understand past and present rates of population growth and to predict future rates, it is necessary to have an understanding of past and present rates of birth, death and migration. More broadly, demographic events affect the composition of the population according to a wide range of characteristics: age, location, marital or relationship status, parenthood status, education, employment, occupation, industry employed in, illness, disability, housing, ethnicity, religion, and so on. Population characteristics in turn influence a wide variety of other behaviours such as consumption, voting, and leisure. 
In recent times, a great deal of attention has been focused on the demographic phenomenon of population ageing and its implications. Ageing is fundamentally the consequence of changes in age structure brought about by a long history of fertility decline, a history as long as 100 years. For example, ageing in Australia in the next 30 years is the consequence of changes in birthrates from the 1930s onwards. In this example, demography is concerned with very long-term change. Ageing, unlike most other demographic changes, is highly predictable because of its long-term nature; ageing is already built into the existing age structure of the population and eventuates simply by people alive today getting older with no decision-making being involved.

\section{Policy: Mitigation and adaptation}

Policy in demography is concerned with the implementation of measures that might influence the course of demographic decision-making and hence influence the course of demographic change (mitigation). As examples of mitigation policy, the birthrate may be influenced negatively through the provision of methods of contraception or positively through benefits provided to those having children. International movements of population are enhanced or constrained by national immigration policies. Public health policy has the aim of reducing rates of mortality and morbidity. Extension of education will be influenced by compulsory schooling or by means of assisting young people to stay in education. Population growth in a particular locality will be influenced by the availability of jobs or housing.

Mitigation policies are potentially controversial. In the age of eugenics, policy called for fertility rates to be lowered among people with so-called 'inferior' characteristics. Government family planning programs have been coercive and family size limitation has been associated with sex-selective childbearing. Today, many countries are attempting to increase their birthrates through policies that redistribute public resources to those who have children. Governments prevent or restrict non-citizens from entering their country, often using draconian measures. Or they run sophisticated immigration programs designed to attract highly skilled people from other countries. Some governments restrict the movement of people within the country or sometimes they sponsor such movement. Laws related to sexual behaviour, abortion or divorce can be controversial. More generally, it is often suggested that governments have no business intervening in the private (demographic) affairs of their citizens. In simple terms, mitigation policy is difficult and not suited to the faint-hearted practitioner. 
Because demographic mitigation policies are often directed to the most intimate or fundamental areas of people's lives, demography becomes associated with ethics and human rights. For example, studies in demography are concerned with such issues as the provision of reproductive health rights to all members of a population, social practices that slow the reduction of maternal mortality, human trafficking, the closing of borders against family reunion and the relative rights of citizens and non-citizens.

On safer ground, demographic policy is also concerned with adjusting to the consequences of demographic decision-making (adaptation). A very large segment of the activities of government is related to adaptation to demographic change including provision of housing, transport, infrastructure, populationrelated environmental initiatives, energy and water use, food production, provision of educational institutions, location of shops and services, aged care facilities and hospitals. Demographers become involved in these decisions of government through the forecasting of future needs based upon estimation of future demographic change.

In addressing population policy itself, governments are often trading off between mitigation and adaptation to demographic changes. For example, the government of Japan for many years has been attempting unsuccessfully to increase the nation's birthrate but now it is planning for the very old society that Japan's very low fertility will generate. Following similar unsuccessful attempts to raise the birthrate, the Singapore government is turning to largescale immigration. Likewise, in 2011, the Australian Government in stating its population policy put all its emphasis upon adaptation:

It is more useful for governments, businesses and communities to focus on ways of improving our wellbeing, protecting our environment and making better use of the resources we have, rather than trying to determine an absolute limit to our population and focusing efforts on restricting growth in order to not exceed this 'limit'. ${ }^{1}$

In contrast, over the past 40 years, many developing country governments have put considerable effort, often very successfully, into family planning programs in order to reduce birthrates and population growth. The fall in birthrates from high levels to contemporary relatively low levels over the past 40 years has been one of the most spectacular successes of mitigation policy in human history. If the world birthrate had remained at its 1970 level, the population of the world in 2050 would have been 16 billion compared with a current projection of the 2050 population of 9 billion.

1 Department of Sustainability, Environment, Water, Population and Communities (2011) 25. 


\section{Forecasting future change}

The ultimate in the study of change is predicting future change. Because of the urgency of the planning needs of government as referred to above, demographers become involved in forecasting future demographic change. Booth (2006) provides a review of methods of forecasting demographic change. She describes three basic approaches to demographic forecasting: extrapolation of past trends, expectation of future behaviour provided by respondents in surveys or through the opinions of experts (Bayesian models), and theory-based structural modelling involving exogenous variables. A fourth approach, not forecasting in Booth's terms, is to make projections of the future based upon a range of reasonable but hypothetical scenarios (assumptions) about the future. With this last approach, the approach used by most national statistical offices, users are invited to make their own choices from among the various scenarios provided.

With a long history of a wide range of error in demographic forecasts or projections, some demographers favour stochastic projections that provide a central forecast with a range of predicted error around the forecast (Hyndman and Booth 2008, Bell et al. 2011). Using stochastic projections, 95 per cent confidence limits can be placed around predicted future levels of population. However, the 95 per cent confidence limits for Australia's population predicted in stochastic population projections by Hyndman and Booth (2008) and by Bell et al. (2011) do not even overlap with each other, despite just a three-year difference in the publication of their results. Despite claiming to build in the conception of risk, this example indicates that stochastic projections claim a spurious degree of accuracy. These two projections differed dramatically from each other because, between the two projections, Australia's international migration level rose very considerably. In both these cases, the projections were strongly influenced by contemporary demography and, despite using different methods to project the future, the conclusion that contemporary demography would extend into the distant future prevailed. Thus, in considering the future, demographers seem to be reluctant to view it as radically different from the present. In this aspect of change, demographers are not well equipped in theory or in method. 


\section{References}

Becker, G (1981) A treatise on the family. Harvard University Press, Cambridge MA.

Bell, M, Wilson, T and Charles-Edwards, E (2011) Australia's population future: probabilistic forecasts incorporating expert judgment. Geographical Research 49(3): $261-75$.

Bongaarts, J and Feeney, G (1998) On the tempo and quantum of fertility. Population and Development Review 24(2): 271-91.

Booth, H (2006) Demographic forecasting: 1980-2005 in review. International Journal of Forecasting 22(3): 547-81.

Clark, J (2003) Uncertainty and variability in demography and population growth: a hierarchical approach. Ecology 84(6): 1370-81.

Department of Sustainability, Environment, Water, Population and Communities (2011) Sustainable Australia — sustainable communities. A sustainable population strategy for Australia. Commonwealth of Australia, Canberra.

Hyndman, R and Booth, H (2008) Stochastic population forecasts using functional data models for mortality, fertility and migration. International Journal of Forecasting 24(3): 323-42.

Klobas, J (2011) The theory of planned behaviour as a model for reasoning about fertility decisions. Vienna Yearbook of Population Research 9(1): 47-54.

Landry, A (1945) Traite de demographie. Payot, Paris.

McDonald, P (2000) Gender equity, social institutions and the future of fertility. Journal of Population Research 17(1): 1-16.

McDonald, P and Kippen, R (2011) Forecasting births. Feature article, ABS Catalogue Number 2051.0. Australian Bureau of Statistics, Canberra.

Preston, S, Heuveline, P and Guillot, M (2001) Demography: measuring and modeling population processes. Blackwell Publishing, Oxford.

Todaro, M (1969) A model of labour migration and urban unemployment in less developed countries. The American Economic Review 59(1): 138-48.

Uhlenberg, P (1996) Mutual attraction: demography and life-course analysis. The Gerontologist 36(2): 226-9. 
This text is taken from Change! Combining Analytic Approaches with Street Wisdom, edited by Gabriele Bammer, published 2015 by ANU Press, The Australian National University, Canberra, Australia. 